\title{
A preliminary study of contemporary binders by Time Resolved Laser Induced Fluorescence (TR-LIF) spectroscopy: characterization of the painting Nascita Della Forma by Nato Frascà
}

\author{
Martina Romani ${ }^{\star}$, Marco Marinelli, Alessandra Pasqualucci, \\ Gianluca Verona-Rinati \\ INFN-Department of Industrial Engineering, University of Rome "Tor Vergata", Via del Politecnico 1, \\ 00133, Rome, Italy \\ * Corresponding author: martina.romani@uniroma2.it
}

\begin{abstract}
In this work, an original study of contemporary binders by Time Resolved Induced Fluorescence Spectroscopy (TR-LIF) is presented. Specifically, fluorescence emission spectra of three classes of binders, commonly employed in contemporary artworks, such as acrylic, vinyl and natural ones, were investigated. The obtained results allow identifying each family through the study of their characteristic emission wavelengths and decay times. Finally, the capability of the TR-LIF technique was tested on a real artwork: Nascita Della Forma (Birth of the Form) by Nato Frascà (1962), housed in the MACRO-Museo d'Arte Contemporanea di Roma (Museum of Contemporary Art in Rome). The above-mentioned painting is characterized by several craquelures, probably due to the overlapping of materials with different chemical and physical properties. The spectra acquired on the selected painting are compared to the ones recorded from laboratory samples, in order to characterize the binders used by the artist.
\end{abstract}

Keywords: contemporary artworks, contemporary binders, Laser Induced Fluorescence Spectroscopy, Time Resolved Laser Induced Fluorescence Spectroscopy, UV Fluorescence Imaging Analysis

\section{Introduction}

A major problem encountered in the conservation of contemporary paintings is the identification of their material composition. This is due to the lack of information provided by the artists in this respect [1]. Indeed, during the $19^{\text {th }}$ century, several new synthetic materials became available on the market, often mixed in tubes and characterized by unknown compositions [2]. Among all these products, acrylic and vinyl polymers probably represent the most used binders in contemporary paintings due to their advantages of fast drying, high resistance and easy coating [3]. However, despite the great popularity of such polymeric binders, many artists still preferred to use the traditional ones, as linseed oil or dammar varnish, and it was usual to find these binders employed 
together with the synthetic ones [4-6]. The use of different components at the same time often results in common damages on the painted surface, such as craquelures, i.e. a traditional degradation of acrylic paint on an oil one [4]. As a consequence, the binder identification is mandatory in order to plan appropriate conservation and restoration strategies.

Laser Induced Fluorescence (LIF) is a non-destructive technique adopted in the investigation, characterization and preservation of cultural heritage thanks to its peculiar advantages of high sensitivity, non-invasiveness and prompt response $[7,8]$. In particular, after an absorption of UV radiation, such a technique allows recording characteristic emissions produced by luminescent materials, thus providing compositional information about the principal components of the pictorial layers [9-11]. However, a limit of LIF analysis shows up when a mix of multi-material samples is investigated, making it difficult to assign each spectral signatures to specific components. Moreover, synthetic binders often present intense fluorescence bands that could cover possible weak emissions from other compounds [12]. Therefore, the emission wavelength alone is not enough to obtain a complete characterization of the analyzed materials.

In this work, the use of the Time Resolved Laser Induced Fluorescence spectroscopy (TR-LIF) is proposed to overcome the above-mentioned issue. Such a technique allows discriminating among emissions from different compounds and analyzing the time evolution of their fluorescence spectra. In particular, in TR-LIF the characterization of binders is performed by studying their typical emission wavelengths and decay times [13-16]. The experimental results confirm the capability to isolate specific contribu- tions from the investigated constituents by a TR-LIF analysis.

In order to verify the reliability of our laboratory results, the painting named Nascita Della Forma (Birth of the Form) by Nato Frascà (1962), hosted in MACRO-Museo d'Arte Contemporanea di Roma (Museum of Contemporary Art in Rome), was analyzed. The picture, in well-defined sections of its surface, is characterized by several craquelures, probably due to the use of different mixtures selected by the artist himself. The results obtained in the present study allowed updating the technical documentation about the artwork and giving useful information to restorers in order to adopt proper conservation and restoration strategies.

\section{Materials and methods}

\subsection{Materials}

\section{Laboratory samples}

In this work, nine synthetic and natural binders are investigated. They were chosen for their common employ in contemporary artworks as binding media [17]. As reported in Table 1 , they are divided in three different classes, according to their chemical composition:

- Acrylic resins: Primal B60-A, Acrytal C12, Primal AC 35, Plextol D 498;

- Vinyl resins: Vinavil, Vinyl Glue, Vinil Pritt;

- Natural binder: linseed oil, dammar varnish.

Each binder was applied on a black cardboard support to perform a preliminary study. Such support was chosen in order to isolate the spectral behavior of pure binders. This is because the negligible fluorescence emission of the cardboard and the low 
penetration depth of the UV radiation allow performing a superficial analysis of the pictorial layers, excluding any contribution arising from the support itself [18].

\section{The painting Nascita Della Forma}

The capability of the TR-LIF technique was tested on the painting Nascita Della Forma (Birth of the Form) by Nato Frascà, 1962, preserved at MACRO (Fig. 1). This work of art was realized in 1962 in Palermo (Sicily), before the establishment of Gruppo 1, by Frascà and other artists $[19,20]$. The above-mentioned painting is classified by the artist himself as "oil on canvas", as reported in the technical documentation of the museum. However, the pictorial layer is actually characterized by several craquelures, a typical degradation caused by the overlapping of different binders (Fig. 2). In particular, such a degradation is observable in two specific areas, corresponding to the orange and light blue pigments. Restorers supposed that these

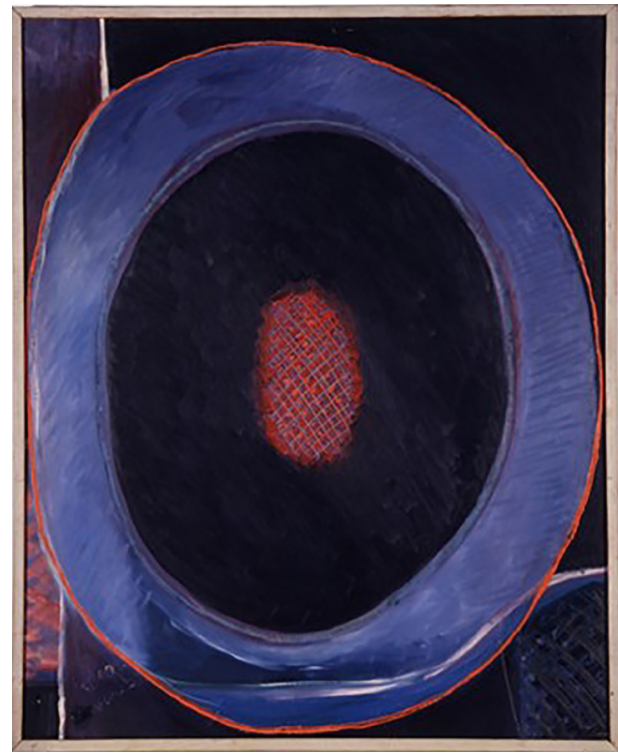

Fig. 1. Nato Frascà, Nascita Della Forma (Birth of the Form), 1962, MACRO.

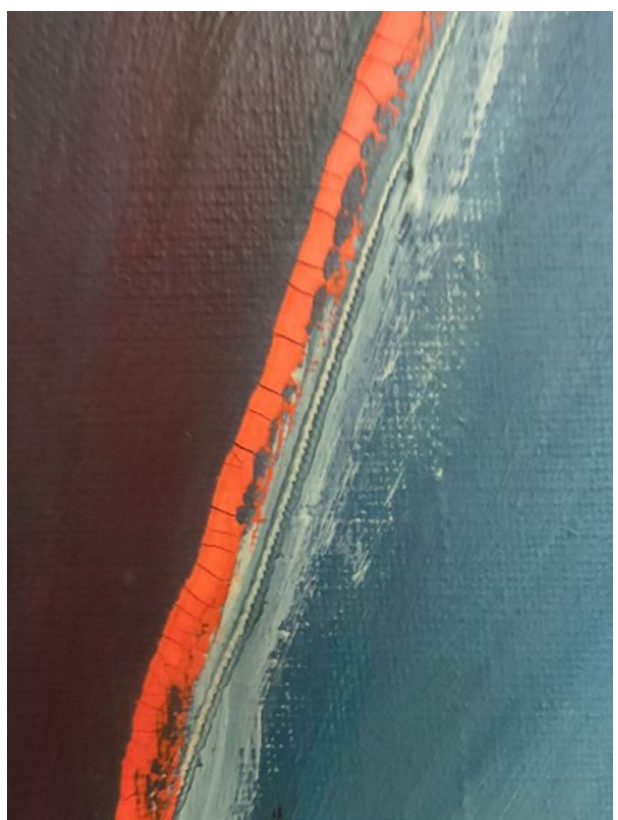

Fig. 2. Nato Frascà, Nascita Della Forma (Birth of the Form), detail of craquelures.

pigments were probably combined with a different binder as compared to the one chosen for the other mixtures used in the painting. Indeed, an aim of this work is to characterize such a binder, which might be responsible of the observed surface degradation.

\subsection{Methods}

\section{TR-LIF set up}

The TR-LIF experimental set up (Fig. 3) allows the acquisition of fluorescence spectra emitted during a well-defined time window with respect to the laser pulse. In particular, both the gate delay (i.e. delay time from the laser pulse and the acquisition start) and the gate window (i.e. aperture time) can be properly selected with a resolution of few ns.

In this work, emission spectra were acquired by using $220 \mathrm{~nm}$ as excitation wavelength, with an average laser pulse energy of 
Table 1. Summary of the investigated samples and TR-LIF analysis results: emission peak wavelengths and estimated decay times

\begin{tabular}{|c|c|c|c|c|}
\hline Class & Sample & Description & LIF analysis: no delay & LIF analysis: $30 \mathrm{~ns}$ delay \\
\hline \multirow{4}{*}{ 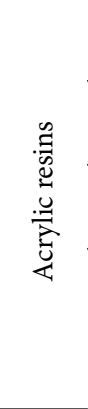 } & $\begin{array}{l}\text { Primal } \\
\text { B60-A }\end{array}$ & $\begin{array}{l}\text { Ethylacrilate-co-methacrylate } \\
\text { made by Rhom and Has }\end{array}$ & $\begin{array}{l}280 \mathrm{~nm} \text {; intermediate } \\
294 \mathrm{~nm} \text {; fast }\end{array}$ & $280 \mathrm{~nm}$; intermediate \\
\hline & $\begin{array}{l}\text { Acrytal } \\
\text { C12 }\end{array}$ & $\begin{array}{l}\text { Aqueous acrylic resin dispersion } \\
\text { made by Iridon }\end{array}$ & $280 \mathrm{~nm}$ : intermediate & $280 \mathrm{~nm}$; intermediate \\
\hline & $\begin{array}{l}\text { Primal } \\
\text { AC } 35\end{array}$ & $\begin{array}{l}\text { Methylmethacrylate made by } \\
\text { Kremer Pigmente }\end{array}$ & $280 \mathrm{~nm}$; intermediate & 310-350: slow \\
\hline & $\begin{array}{l}\text { Plextol } \\
\text { D498 }\end{array}$ & $\begin{array}{l}\text { Aqueous pure acrylic dispersion } \\
\text { of a copolymer based on ethyl } \\
\text { acrylate and methyl methacrylate } \\
\text { by Kremer Pigmente }\end{array}$ & $280 \mathrm{~nm}$; intermediate & $310-350 \mathrm{~nm}$; slow \\
\hline \multirow{3}{*}{ 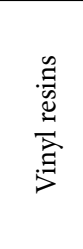 } & Vinavil & Vinyl Acetate by Vinavil & $\begin{array}{l}280 \mathrm{~nm} \text { : intermediate } \\
320-360 \mathrm{~nm} \text { : slow }\end{array}$ & $\begin{array}{l}280 \mathrm{~nm} \text { : intermediate } \\
320-360 \mathrm{~nm} \text {; slow }\end{array}$ \\
\hline & Vinyl Glue & $\begin{array}{l}\text { Emulsion of polyvinyl acetate and } \\
\text { polyvinyl alcohol }\end{array}$ & $\begin{array}{l}280 \mathrm{~nm} \text {; intermediate } \\
320-360 \mathrm{~nm} \text {; slow }\end{array}$ & $\begin{array}{l}280 \mathrm{~nm} \text {; intermediate } \\
320-360 \mathrm{~nm} \text { : slow }\end{array}$ \\
\hline & Vinil Pritt & $\begin{array}{l}\text { Ethylene-vinyl acetate (EVA) by } \\
\text { Henkel Italia (Milan, Italy) }\end{array}$ & $\begin{array}{l}280 \mathrm{~nm} \text {; intermediate } \\
320-360 \mathrm{~nm} \text {; slow }\end{array}$ & $\begin{array}{l}280 \mathrm{~nm} \text {; intermediate } \\
320-360 \mathrm{~nm} \text {; slow }\end{array}$ \\
\hline \multirow{2}{*}{ 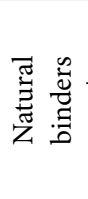 } & Linseed oil & $\begin{array}{l}\text { Refined linen seed extract by } \\
\text { Maimeri (Milan, Italy) }\end{array}$ & $270-310 \mathrm{~nm}$ : fast & - \\
\hline & $\begin{array}{l}\text { Dammar } \\
\text { varnish }\end{array}$ & $\begin{array}{l}\text { Natural dammar resin with } \\
\text { turpentine by Maimeri (Milan, } \\
\text { Italy) }\end{array}$ & $270-310 \mathrm{~nm}$; fast & - \\
\hline
\end{tabular}

about $3 \mu \mathrm{J}$ and a $20 \mathrm{~Hz}$ repetition rate. Such a laser wavelength was chosen because the emission of the studied binders exhibit characteristic features in the $250-360 \mathrm{~nm}$ spectral region [21], which can be fully appreciated by using a shorter excitation wavelength. On the contrary, longer wavelengths would result in a partial loss of spectral information from the investigated materials. The laser beam is focused on the sample surface with a spot size about $0.3 \times 1 \mathrm{~mm}^{2}$ (Fig. 3). For each sample two spectra were acquired. The first one was taken immediately after the laser pulse (no delay), while the other with a 30 ns delay ( 30 ns delay). In both cases, 20 ns gate window was used. In order to achieve a good statistic, each acquired spectrum was integrated over 2000 laser pulses. The above gate window and delay time were selected after preliminary TR-LIF measurements, performed to assess the typical time evolution of the investigated samples emission spectra. A rough estimation of the decay times was then calculated, as reported in the following (see section 3). However, it should be pointed out that this work can be considered a preliminary study about common contemporary binders, so that only a qualitative classification of their decay times is reported. For this reason, a more detailed characterization of the samples is recommended to achieve a comprehensive database and further studies are currently ongoing in our laboratory.

It is worth noting that the TR-LIF results reported in the present work were obtained by a bench setup facility available in our 


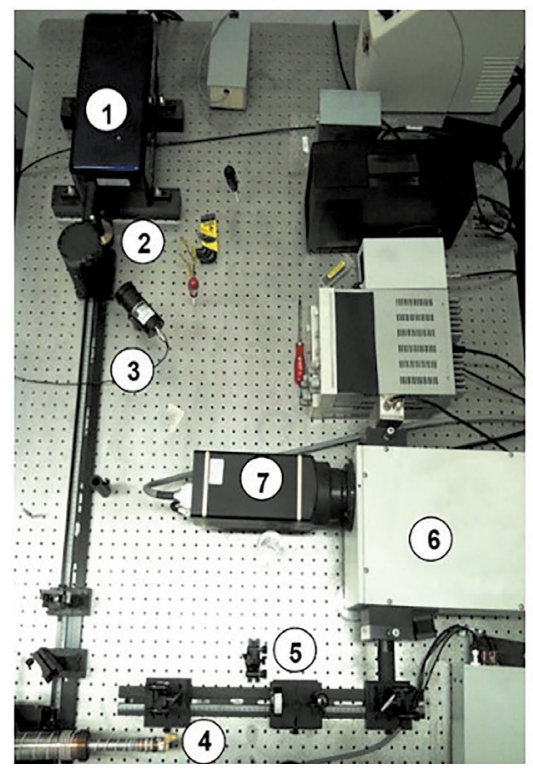

\begin{tabular}{|l|l|}
\hline Excitation wavelength & $220 \mathrm{~nm}$ \\
\hline Duration of the laser pulse & $3 \mathrm{~ns}$ \\
\hline Energy & $3 \mu \mathrm{J}$ \\
\hline Investigated area & $0.3 \times 1 \mathrm{~mm}^{2}$ \\
\hline Repetition rate & $20 \mathrm{~Hz}$ \\
\hline Laser fluence & $1 \mathrm{~mJ} / \mathrm{cm}^{2}$ pulse \\
\hline Gate aperture time & $20 \mathrm{~ns}$ \\
\hline
\end{tabular}

Fig. 3. TR-LIF experimental set-up and measurements conditions employed in this work: (1) $210-2400 \mathrm{~nm}$ optical parametric Oscillator Nd:YAG tunable laser, producing approximately 3 ns wide pulses (Opolette laser by Opotek); (2) Beam splitter; (3) Pyrometer for beam intensity monitoring; (4) Sample holder; (5) Off-axis parabolic mirrors for beam focalization and photoluminescence light recoil; (6) Spectrometer (SpectraPro 3001, Roper Scientific); (7) PI-MAX Roper Scientific gated multi-channel-plate/ CCD camera.

lab. A new portable setup is currently being realized by our group, so to allow in situ characterization of artworks.

\section{UV Fluorescence Imaging Analysis System}

Ultraviolet (UV) fluorescence imaging analysis was performed by using a NIR-converted Nikon D7100 camera with a Silicon sensor (Fig. 4). The UV fluorescence images were acquired by illuminating the painted surface with an UV lamp, characterized by an excitation wavelength of about $400 \mathrm{~nm}$. When recording images, the camera was equipped with two superimposed filters: a long pass filter at $500 \mathrm{~nm}$ and an infrared (IR) cut filter at $680 \mathrm{~nm}$. The above-mentioned filters system allows excluding any possible interference from the UV and IR regions respectively during the acquisitions [22].

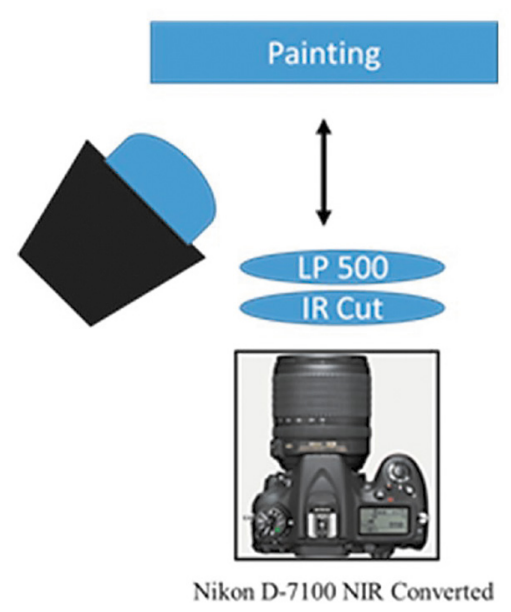

Fig. 4. UV Fluorescence imaging analysis system: Nikon D7100-NIR converted; sensor type: Si; spectral band: 370-1100nm; resolution: 24.1 MegaPixel; UV lamp centered at about $400 \mathrm{~nm}$; filters LP 500 and IR Cut. 


\section{Results}

As mentioned above, the TR-LIF spectra of each analyzed sample were measured in order to study the characteristic fluorescence emissions and decay times from specific binders. The duration of the gate aperture and delay time were chosen after preliminary TR-LIF measurements to investigate the typical time evolution of the studied emissions. The decay time is estimated for each fluorescence band as:

$$
\tau=\frac{\left(\mathrm{t}_{2}-\mathrm{t}_{1}\right)}{\ln \left(I_{1} / \mathrm{I}_{2}\right)}
$$

where and represent the recorded light powers integrated in the time intervals (; $+\Delta \mathrm{t})$ and $(;+\Delta \mathrm{t})$, respectively. It is worth highlighting that this equation is valid only for single-exponential decay and it is used to obtain a rough estimation of the decay times of the investigated sample. However, as mentioned in section 2.2.1, the spectra acquired with no delay and $30 \mathrm{~nm}$ delay can be considered sufficient to obtain such a qualitative estimation. Specifically, the emission decay times are classified in three different categories: fast, intermediate and slow. In particular, the decay time is considered fast if it is shorter than $9 \mathrm{~ns}$, intermediate if it is included between 9 and $15 \mathrm{~ns}$ and slow if it is longer than $15 \mathrm{~ns}$.

It should be pointed out that some spectra reported below and acquired with no delay showed a relatively weak peak at $440 \mathrm{~nm}$. This contribution is due to the laser source, which was not totally filtered out. In addition, a large emission band between $400-500 \mathrm{~nm}$ is observed for all the analyzed samples. However, similar bands are already reported in literature for several organic compounds, so that they cannot be considered as distinctive signatures of the investigated materials
[23]. For the above reasons, both spectral features will not be discussed in detail in the following part of the text.

\subsection{Laboratory results}

The emission of the cardboard support was studied at first in order to exclude any significant contribution during the fluorescence acquisitions. In Fig. 5, the spectra obtained

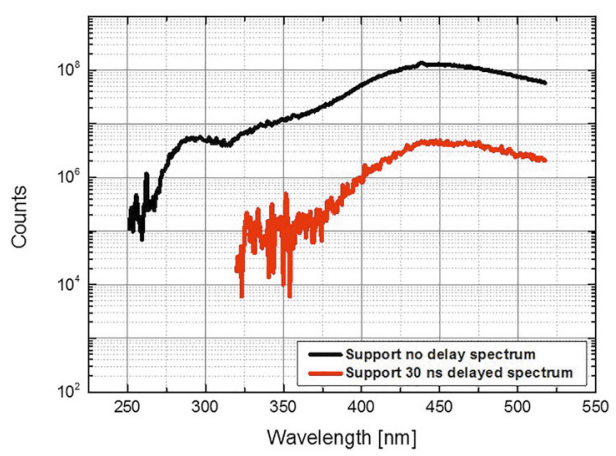

Fig. 5. TR-LIF cardboard support spectra: no delay spectrum (black line), $30 \mathrm{~ns}$ delay spectrum (red line).

from the cardboard are shown: the black line corresponds to spectrum acquired immediately after the laser pulse, no delay spectrum, while the red line refers to the one recorded after $30 \mathrm{~ns}, 30 \mathrm{~ns}$ delayed spectrum. In the former curve (no delay) it is possible to appreciate a weak and wide band at about $270-300 \mathrm{~nm}$. Such an emission is not present in the delayed spectrum, because of its fast decay time, which is shorter than 9 ns. Moreover, a large band between $400-500 \mathrm{~nm}$ is also observed, as previously discussed [23]. The cardboard contribution can thus be considered as negligible due to the lack of meaningful emissions in the UV region, where the contemporary binders fluorescence emission is usually expected [24]. 
In Fig. 6, all the spectral features obtained for the four analyzed acrylic binders are reported altogether. The most intense fluorescence emission is observed for the Primal B60-A (black line), showing two bands in the no delay spectrum, centered at about $280 \mathrm{~nm}$ and at $294 \mathrm{~nm}$ respectively. However, in the delayed spectrum (Fig. 6B; black line), the latter emission shows a fast reduction of its fluorescence intensity (approximately one order of magnitude in $20 \mathrm{~ns}$ ) and a drift of the peak position towards shorter wavelength. This behavior could be explained considering two superimposed spectral contributions centered at $280 \mathrm{~nm}$ and $294 \mathrm{~nm}$ respectively, the second one being characterized by a faster decay time.

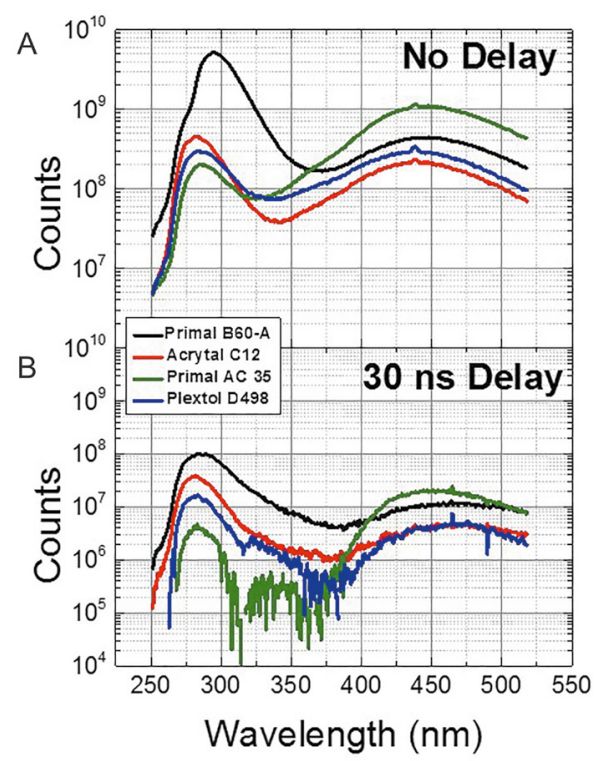

Fig. 6. TR-LIF spectra of the analyzed acrylic binders: Primal B60-A (black line), Acrytal C12 (red line), Primal AC 35 (green line), Plextol D498 (blue line).

The same emission centered at $280 \mathrm{~nm}$, already evident for the Primal B60-A and characterized by an intermediate decay time, is observed in the other three analyzed acrylic binders as well: Acrytal C12 (red lines), Primal AC35 (green lines) and Plextol D498 (blue lines). In addition, the Primal AC35 and the Plextol D498 spectra show a further band between $310-350 \mathrm{~nm}$, only appreciable in the delayed spectra due to its slow decay time. These different behaviors of Primal B60-A (the fast emission at 294 nm), Primal AC35 and Plextol D498 (the slow emission at $310-350 \mathrm{~nm}$ ) are probably due to several compounds possibly contained into the binders themselves. Indeed, in Fig. 6 it is possible to appreciate that all the studied binders are characterized by an intense emission at $280 \mathrm{~nm}$, described by an intermediate decay time.

The spectral behaviors obtained from the vinyl binders are reported in Fig. 7. In particular, lines presented in Fig. 7A correspond to the spectra acquired immediately after the laser pulse, while the delayed ones are showed in Fig. 7B. All the curves exhibit the same emission band at about $280 \mathrm{~nm}$, already observed for the acrylic class. Such an emission is characterized by an intermediate decay time, as it is possible to appreciate from the delayed spectra in Fig. 7B. In addition, differently from the acrylic ones, the vinyl binders show a further emission band in all the delayed acquisitions, in the $320-360 \mathrm{~nm}$ range. Such a band is also characterized by a slow decay time, longer than $15 \mathrm{~ns}$. Then, the presence at once of both the emission bands in the fluorescence spectra $(280 \mathrm{~nm}$ and $320-360 \mathrm{~nm}$ ) could be considered characteristic for the vinyl resins class.

At last, the spectral features observed for the selected natural binders, linseed oil and dammar varnish are reported in Fig. 8A and $8 \mathrm{~B}$, respectively. It must be pointed out that both the spectral signatures appear very similar between them and to the support ones. Indeed, they show a weak intensity emission 


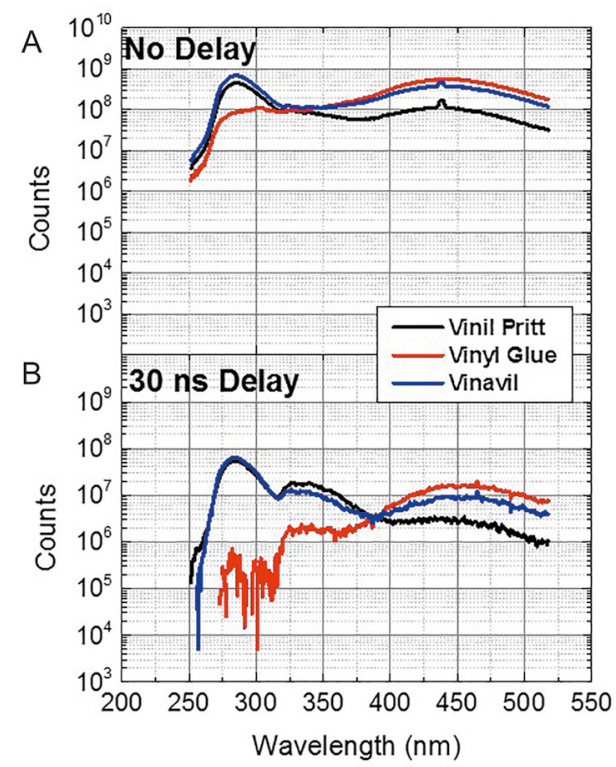

Fig. 7. TR-LIF spectra of the investigated vinyl binders: Vinil Pritt (black line), Vinyl Glue (red line), Vinavil (blue line).

in the UV region if compared to the ones observed for the acrylic and vinyl classes. It should be noticed that the above-mentioned natural binders are almost completely absorbed by the cardboard, so that an extremely thin binder layer is present on the support surface. This implies that the fluorescence emission from the support is probably not negligible in this case, making it difficult to extract characteristic information from the obtained results. For the above reason, it might be interesting to perform a systematic investigation on these natural binders on different supports and as a function of the laser excitation wavelength.

One of the turning points of this research regards the potential capability of the TR-LIF to identify signatures from mixed compounds (i.e.: binders and pigments). Therefore, each of the nine binders previously analyzed was mixed with some selected

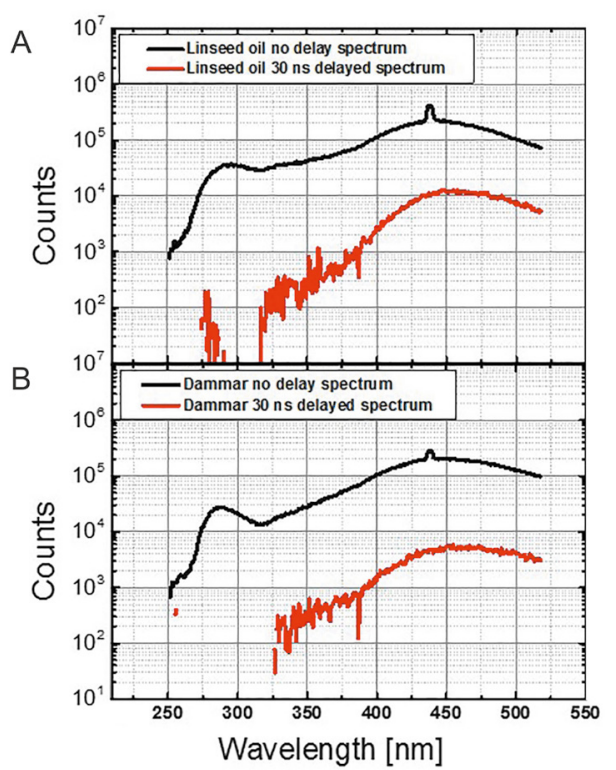

Fig. 8. TR-LIF spectra of the studied natural binders: A) linseed oil, B) dammar varnish in turpentine. For each graph, the black line represents the no delay spectrum and the red line the 30 ns delay spectrum.

pigments, usually employed in contemporary painted artworks. In Fig. 9, the spectra obtained from a mixture of Zinc white and an acrylic binder is reported, as an example. In this graph, it is possible to recognize the characteristic acrylic emission peak centered at $280 \mathrm{~nm}$. Moreover, a further peak at $380 \mathrm{~nm}$ is appreciable, corresponding to the Zinc band gap, as reported in literature [25, 26]. The delayed spectrum (red line) shows that the studied compounds are defined by an intermediate (acrylic binder) and decay time (Zinc oxide), respectively. In addition, the obtained results proved that there is no evidence of quenching effects or spectral interactions among the single constituents of the studied mixture. Indeed, the measured spectra consist in a linear combination of the emissions obtained from a mixture of pure binder and pigment powder. 


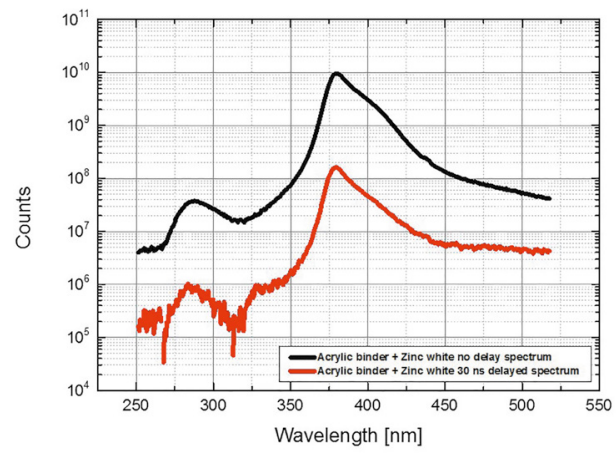

Fig. 9. TR-LIF spectrum of an acrylic binder mixed with Zinc white with no delay (black line) and with 30 ns delay (red line).

\subsection{Case Study}

The laboratory results were then compared to the ones acquired on the painting Nascita Della Forma (Birth of the Form), by Nato Frascà (1962), in order to characterize the binders employed by the artist on its painted surface, classified by himself as "oil on canvas" (Fig. 1). As shown in the magnification (Fig. 2 ), the surface is characterized by a degradation of painted layer, corresponding to the fluorescent orange and light blue pigments. Such a behavior suggests a probable use of different binders in the corresponding areas, as compared to the one chosen for the painted surface. At first, the fluorescence image of the pictorial layers was recorded in order to map fluorescence emissions of different compounds, thus guiding the TR-LIF measurements. In Fig. 10, it is possible to appreciate how the orange and light blue pigments are characterized by an intense fluorescence that other pigments do not show. These behaviors are indicating a possibly different composition of the above-mentioned paints [27].

The TR-LIF acquisitions were recorded on the painted surface by using the same measurements conditions applied for the laboratory samples. The obtained spectra are reported in Fig. 11, where the black line corresponds to no delay spectrum, while the red one is for $30 \mathrm{~ns}$ delayed spectrum. Both the curves exhibit a band centered at $280 \mathrm{~nm}$, which is also characterized by an intermediate decay time. A further intense peak at 380 $\mathrm{nm}$, described by a fast decay time, which is compatible with the emission from the Zinc oxide reference sample shown in Fig. 9 and with previous results reported in literature $[25,26]$. This is also confirmed by additional XRF measurements performed on the same orange and light blue pigments, not reported here.

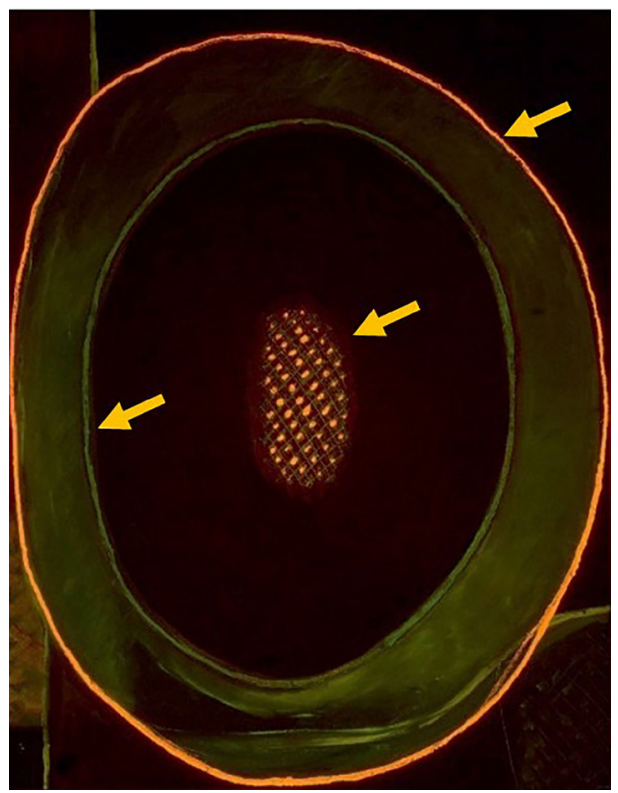

Fig. 10. Fluorescence image of the painting Nascita Della Forma (Birth of the Form).

A comparison between the results discussed in section 3.1 with the ones obtained from Nascita Della Forma (Birth of the Form) suggests that the binder used for the two selected paints is an acrylic one due to the characteristic emission band at $280 \mathrm{~nm}$. Such 


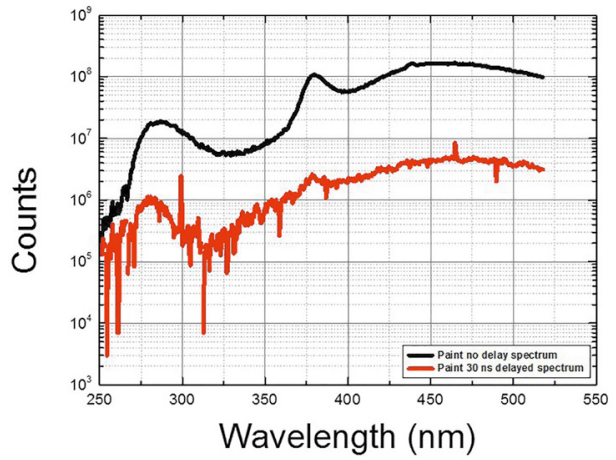

Fig. 11. TR-LIF spectra acquired on the painting Nascita Della Forma (Birth of the Form): no delay spectrum (black line), 30 ns delay spectrum (red line).

a hypothesis is also supported by observing the degradation corresponding to the orange and light blue pigments, characterized by the presence of several cracks [28].

\section{Conclusion}

In this work, the TR-LIF spectroscopy is demonstrated to be a valid tool to study different classes of binders employed in the contemporary art. Distinctive spectral features were observed from acrylic, vinyl and natural binders. Specifically, an emission band centered at $280 \mathrm{~nm}$, and defined by an intermediate decay time, characterized all the spectra from acrylic binders. The same band was also observed for the investigated vinyl compounds, which additionally showed a further emission band between 320-360 $\mathrm{nm}$ in the $30 \mathrm{~ns}$ delayed spectra, defined by a slow (>15 ns) decay time. This last distinctive feature can be used in order to distinguish the vinyl compounds from the acrylic ones. No peculiar fluorescent emissions were observed instead from the natural binders investigated in the present study due to the similarity of their spectral emissions to the cardboard support ones. Such a behavior was probably due to an unfitting excitation wavelength. Finally, the laboratory results were compared with the ones acquired on the contemporary painting Nascita Della Forma (Birth of the Form) by Nato Frascà. The study of UV fluorescence images before and the TR-LIF measurements after allowed identifying the acrylic binders employed in the painted surface, thus providing an important information in view of a proper conservation of the investigated artwork.

It should be pointed out that further studies are mandatory in order to establish the specific acrylic and vinyl fluorophores responsible for the observed fluorescence emissions. Nevertheless, the achieved classification represents a good starting point towards the realization of a dedicated database for contemporary materials and allows improving technical information about artworks. In conclusion, the TR-LIF spectroscopy analysis should be considered a valid tool for the investigation, characterization and preservation of contemporary artworks.

\section{Acknowledgments}

This study was made possible thanks to a partnership with the MACRO-Museo d'Arte Contemporanea di Roma (Museum of Contemporary Art in Rome). The authors wish to thank the Director of the MACRO, Dr. Federica Pirani, and the art experts of the MACRO, Dr. Antonia Rita Arconti and Dr. Paola Coltellacci for their helpful collaboration.

\section{References}

[1] C. Cucci, L. Bigazzi, M. Picollo, "Fiber Optic Reflectance Spectroscopy as a non-invasive tool for investigating plastics degradation in contemporary art 
collections: A methodological study on an expanded polystyrene artwork", Journal of Cultural Heritage, 14 (2013) 290-296, DOI: 10.1016/j.culher.2012.08.003.

[2] T. Learner, "A review of synthetic binding media in twentieth-century paints", The Conservator, 24,(2000), 96-103, DOI: 10.1080/01410096.2000.9995156.

[3] E. Jablonski, T. Learner, J. Hayes, M. Golden, "Conservation concerns for acrylic emulsion paints", Studies in Conservation, 48 (2003) 3-12, DOI: 10.1179/sic.2003.48.Supplement-1.3.

[4] G.C. Scicolone, Il restauro dei dipinti contemporanei, Nardini Editore, Florence 2004.

[5] M. Matteini, A. Moles, La chimica nel restauro. I materiali dellarte pittorica, Nardini Editore, Florence 2007.

[6] L. Mayer, G. Myers, "A Note on the Early Use of Dammar Varnish", Studies in Conservation, 47 (2002) 134-138, DOI: 10.1179/sic.2002.47.2.134.

[7] D. Anglos, C. Balas, C. Fotakis, "Laser spectroscopic and optical imaging techniques in chemical and structural diagnostics of painted artwork", American Laboratory, 31 (1999) 60-67.

[8] A. Nevin, S. Chater, D. Anglos, C. Fotakis, "Analysis of protein-based binding media found in paintings using laser induced fluorescence spectroscopy", Analytica Chimica Acta, 573-574 (2006) 341-346, DOI: 10.1016/j.aca.2006.01.027.

[9] T. Miyoshi, M. Ikeya, S. Kinoshita, T. Kushida, "Laser-Induced Fluorescence of Oil Colours and Its Application to the Identification of Pigments in Oil Paintings", Japanese Journal of Applied Physics, 21 (1982) 1032-1036, URL: http://iopscience.iop. org/1347-4065/21/7R/1032.

[10] A. Romani, C. Celementi, C. Miliani, G. Favaro, "Fluorescence Spectroscopy: A Powerful Technique for the Noninvasive Characterization of Artwork", Accounts of Chemical Research, 43 (2010) 837-846, DOI: 10.1021/ar900291y.

[11] V. Lazic, F. Colao, R. Fantoni, A. Palucci, V. Spizzichino, I. Borgia, B. G. Brunetti, A., Sgamellotti, "Characterisation of lustre and pigment composition in ancient pottery by laser induced fluorescence and breakdown spectroscopy", Journal of Cultural Heritage, 4 (2003) 303-308, DOI: 10.1016/S12962074(02)01212-8.
[12] A. Nevin, I. Osticioli, D. Anglos, A. Burnstock, S. Cather, E. Catellucci, "Raman Spectra of Proteinaceous Materials Used in Paintings: A Multivariate Analytical Approach for Classification and Identification", Analytical Chemistry, 79 (2007) 6143-6151, DOI: $10.1021 / \mathrm{ac} 070373 \mathrm{j}$.

[13] A. Nevin, D. Comelli, G. Valentini, D. Anglos, A. Burnstock,S. Cather, R. Cubeddu, "Time-resolved fluorescence spectroscopy and imaging of proteinaceous binders used in paintings", Analytical and Bioanalytical Chemistry, 388 (2007) 1897-1905, DOI: 10.1007/s00216-007-1402-0.

[14] A. Nevin, D. Anglos, "Assisted interpretation of Laser-Induced Fluorescence spectra of egg-based binding media using total emission fluorescence spectroscopy", Hindawi Publishing Corporation Laser Chemistry, (2006) 1-5, DOI: 10.1155/2006/82823.

[15] R. Ortiz, P. Ortiz, F. Colao, R. Fantoni, M. A. Gómez-Morón, M. A. Vázquez, "Laser spectroscopy and imaging application for the study of cultural heritage murals", Construction and Building Materials, 98 (2015) 35-43, DOI: 10.1016/j.conbuildmat.2015.08.067.

[16] T. Miyoshi, "Fluorescence from Oil Colours, Linseed Oil and Poppy Oil under N2 Laser Excitation", Japanese Journal of Applied Physics, 24 (1985) 371-372.

[17] P. Symour, The Artist's Handbook, Arcturus Publishing Limited, London 2003.

[18] M. Romani, F. Colao, R. Fantoni, M. Guiso, M.L.Santarelli, "Hyperspectral fluorescence for organic pigment characterization in contemporary artwork", Journal of Applied and Laser Spectroscopy, 1 (2014) 29-36.

[19] F. Sossi, Dallocchio al cervello: Gruppo 1 di Roma: Carrino, Frascà, Uncini, Magna Grecia, Taranto 1965.

[20] G. Di Genova, Generazione anni 30, in Storia dellarte italiana del'900: per generazioni, Bora, Bologna 2000.

[21] M. Marinelli, A. Pasqualucci, M. Romani, G. Verona-Rinati, "Time resolved laser induced fluorescence for characterization of binders in contemporary artworks", Journal of Cultural Heritage, 23 (2017) 98-105, DOI: 10.1016/j.culher.2016.09.005. 
[22] A. Cosentino, "Identification of pigments by multispectral imaging; a flowchart method", Heritage Science, 2 (2014) 1-12, DOI: 10.1186/2050-7445-2-8.

[23] D. Comelli, A. Nevin, G. Verru, G. Valentini, R. Cubeddu, "Time-resolved fluorescence spectroscopy and fluorescence lifetime imaging for the analysis of organic materials in wall painting replicas" in: F. Piqué, G. Verri (Eds.), Organic materials in Wall Paintings, Project Report, Getty Conservation Institute 2015, pp. 83 - 96, http://www.getty.edu/conservation/publications_resources/pdf_publications/ pdf/omwp_report.pdf (accessed 22.08.2017).

[24] D. Comelli, G. Valentini, A. Nevin, A. Farina, L. Toniolo, R. Cubeddu, "A portable UV-fluorescence multispectral imaging system for the analysis of painted surfaces", Review of Scientific Instruments, 79 (2008), DOI: 10.1063/1.2969257.

[25] I. Borgia, R. Fantoni, C. Flamini, T. M. Di Palma, A. Giardini Guidoni, A. Mele, "Luminescence from pigments and resins for oil paintings induced by laser excitation", Applied Surface Science, 127-128 (1998), 95-100, DOI: 10.1016/ S0169-4332(97)00616-8.

[26] D. W. Bahnemann, C. Kormann, M. R. Hoffmann, "Preparation and Characterization of Quantum Size Zinc Oxide: A Detailed Spectroscopic Study", The Journal of Physical Chemistry, (1987) 91 3789-3798, DOI: 10.1021/j100298a015.

[27] M. Bacci, M. Picollo, G. Trumpy, M. Tsukada, D. Kunzelman, "Non-Invasive Identification of White Pigments on $20^{\text {th }}$-Century Oil Paintings by Using Fiber Optic Reflectance Spectroscopy", Journal of the American Institute for Conservation, 46 (2007) 27-37, DOI: 10.1179/019713607806112413.

[28] P. M. Whitmore, D. Moran, C. Bailie, "Shrinkage Stresses in Art and Conservation Coatings Based on Synthetic Polymers", Journal of the American Institute for Conservation, 38 (1999) 429-441, DOI: 10.1179/019713699806113402. 